\title{
The Effect of Incontinence Severity on Symptom Distress, Quality of Life, and Pelvic Floor Muscle Function in Turkish Women with Urinary Incontinence
}

\author{
Ceren ORHAN ${ }^{1}$, Serap OZGUL ${ }^{1}$, Emine BARAN ${ }^{1}$, Esra UZELPASACI'1, Gulbala NAKIP¹, Gamze Nalan CINAR ${ }^{1}$, \\ Mehmet Sinan BEKSAC ${ }^{2}$, Turkan AKBAYRAK ${ }^{1}$
}

Ankara, Turkey

\section{ABSTRACT}

OBJECTIVE: The aim of the present study was to compare the differences in symptom distress, quality of life, and pelvic floor muscle function among Turkish women with mild, moderate, or severe urinary incontinence.

STUDY DESIGN: One hundred and twenty women with a diagnosis of urinary incontinence $(54.2 \%$ stress urinary incontinence and $45.8 \%$ mixed-urinary incontinence) participated in the present study. The severity of the urinary incontinence was stratified by the Incontinence Severity Index. The Turkish versions of the Urinary Distress Inventory-6 and the Incontinence Impact Questionnaire-7 were used to assess symptom distress and quality of life, respectively. Pelvic floor muscle strength and endurance were measured using a non-invasive vaginal perineometer.

RESULTS: Symptom distress and quality of life significantly differed among the mild, moderate, and severe urinary incontinence groups $(p<0.001)$. Patients with severe stress urinary incontinence displayed a higher decrease in quality of life than those with mild stress urinary incontinence $(p<0.001)$. Furthermore, severe mixed urinary incontinence had a greater impact on symptom distress and quality of life compared to mild and moderate mixed urinary incontinence $(p<0.05)$. The Incontinence Severity Index score was significantly associated with the Urinary Distress Inventory-6 and Incontinence Impact Questionnaire-7 scores $(p<0.001)$.

CONCLUSION: Urinary incontinence affected the symptom distress and quality of life of patients in proportion to the severity of the symptoms. Therefore, the relationship between the severity of urinary incontinence and patients' quality of life should be evaluated in clinical settings. To prevent the greater influence of incontinence on the quality of life of women with urinary incontinence, early detection of urinary incontinence and early management strategies are essential.

Keywords: Severity, Symptom, Urinary incontinence, Quality of life

Gynecol Obstet Reprod Med 2020;26(1):51-57

${ }^{1}$ Hacettepe University, Faculty of Health Sciences, Department of Physiotherapy and Rehabilitation, ${ }^{2}$ Department of Obstetrics and Gynecology, Ankara, Turkey

Address of Correspondence: Ceren Orhan

Hacettepe University, Faculty of Health

Sciences, Department of Physiotherapy and Rehabilitation, 06100, Ankara, Turkey cerengursen@yahoo.com

Submitted for Publication: Revised for: Publication: Accepted for Publication:

11.02.2019

03.03 .2019

13.03.2019

ORCID IDs of the authors: $\quad$ CO: 0000-0002-9204-8364,

SO: 0000-0002-2362-6773, EB: 0000-0003-4974-6543,

EU: 0000-0002-0960-122X, GN: 0000-0001-5331-786X,

GNC: 0000-0001-8700-2153, MSB: 0000-0001-6362-787X, TA: 0000-0001-5840-5252

\begin{tabular}{|c|c|}
\hline \multirow{3}{*}{ 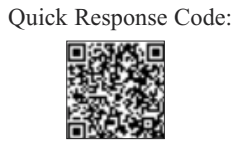 } & Access this article online \\
\hline & $\begin{array}{l}\text { Website: www.gorm.com.tr } \\
\text { e- mail: info@gorm.com.tr }\end{array}$ \\
\hline & DOI:10.21613/GORM.2018.911 \\
\hline
\end{tabular}

How to cite this article: Orhan C, Ozgul S. Baran E. Uzelpasaci E. Nakip G. Cinar GN. Beksac MS. Akbayrak T. The Effect of Incontinence Severity on Symptom Distress, Quality of Life, and Pelvic Floor Muscle Function in Turkish Women with Urinary Incontinence. Gynecol Obstet Reprod Med 2020;26(1):51-57

\section{Introduction}

Urinary incontinence (UI) has been defined as an involuntary leakage of urine (1) and is a common condition worldwide. The most common types of UI have been considered to be stress UI (SUI; the involuntary loss of urine upon effort, physical exertion, sneezing, or coughing), urgency UI (the involuntary loss of urine associated with urgency), and mixed UI (MUI; both SUI and urgency UI; 1). Previous studies have found that the rate of UI prevalence ranges from $16.4 \%$ to $50.3 \%$ in Turkish women (2-5). This variation between studies may be related to different definitions of UI, different methodologies for data collection, or the differences in the demographics of the study populations (6). UI significantly limits the lives of women affected due to the physical, psychological, and social inconveniences (7). The fear of leakage and odor may be related to embarrassment, frustration, depressive mood, psychological distress, and social isolation $(8,9)$. Consequently, the quality of life is significantly affected by the symptoms of UI $(10,11)$. 
In the literature, it has been suggested that the evaluation of the severity of the disease, the symptom distress, and the quality of life of the women affected can be complementary to objective measurements and that subjective outcomes can provide important data for UI management strategies (12). A recent study indicated that mild UI was more highly associated with successful outcomes of conservative treatment compared to moderate or severe UI; therefore, the initial assessment of the disease severity is essential for determining the need for second-line treatments (13). Additionally, improvement in the subjective severity of UI seems to be more important than improvement in objective outcome measurements. Although previous research has examined the variations in quality of life among different types of UI (10), knowledge of the impact of the severity of UI upon symptom distress and quality of life is limited. Additionally, only one study reported that pelvic floor muscle strength, measured by the Brink score, was not related to the severity of incontinence, evaluated by the pad test, in patients with UI (14).

In the literature, previous studies conducted within the Turkish population indicated that the duration of UI $(4,15)$, the amount of leakage $(4,15)$, the frequency of UI episodes (4), and the number of pads (15) were related to the quality of life impairment. However, in these studies, the severity of UI was determined based on patient-reported measurements rather than valid and reliable scales $(4,15)$. Additionally, the association between the severity of UI and pelvic floor muscle function has not been investigated in the Turkish population. To our knowledge, this is the first study to investigate the relationship between the severity of UI and pelvic floor muscle strength and endurance, which was objectively measured in the present study using a perineometer, in Turkish women suffering from UI. For this reason, we aimed to compare the differences in symptom distress, quality of life, and pelvic floor muscle strength and endurance among Turkish women with mild, moderate, or severe UI. In addition, the relationships between the severity of UI and symptom distress, quality of life, and pelvic floor muscle strength and endurance were investigated.

\section{Material and Method}

The present study was designed as a cross-sectional study and conducted at the department of physiotherapy and rehabilitation of Hacettepe University (Ankara, Turkey).

Women who had a diagnosis of symptomatic UI were recruited from the gynecology clinic of Hacettepe University. The eligibility of the patients was determined based on the inclusion and exclusion criteria, and all assessments were performed at the physiotherapy department. Participants who were older than 18 years-of-age, diagnosed with UI, not pregnant and not having given birth in the previous three months, and who sufficiently cooperated during the assessments were included in the present study. The Medical, Epidemiological, and Social Aspects of Aging (MESA) questionnaire was used for the symptomatic diagnosis of UI (16). The MESA questionnaire consists of nine items concerning SUI and six items regarding urgency UI (16). A previous study revealed that there was an $87 \%$ agreement between the MESA questionnaire and clinical assessment (17). The exclusion criteria were determined as follows: (1) > Stage 3 or 4 pelvic organ prolapse (POP); (2) urinary tract infections; (3) neurological diseases; and (4) current oncological diagnosis. The study was conducted in accordance with the Declaration of Helsinki. The local ethics committee of the university approved the study protocol (GO17/820 - Date: 10/10/2017) and written informed consent was obtained from all patients.

\section{Evaluations}

Self-reported information regarding sociodemographic data, including age, education level, marital and working status, and physical characteristics, such as height and weight, were obtained. In addition, smoking habits, gravidity, parity, post-menopausal status, and the duration of UI were recorded.

The incontinence severity index (ISI), developed by Sandvik et al. $(18,19)$, was used to assess the severity of the UI. The frequency of incontinence episodes and the amount of leakage were multiplied to calculate the total score of the ISI $(18,19)$. In accordance with the total ISI score, the severity of UI was categorized as mild (a score of 1-2), moderate (a score of 3-6), or severe (a score of 8-12) $(18,19)$.

The urinary distress inventory-6 (UDI-6) was used to evaluate symptom distress related to UI (20). Additionally, the impact of UI on the patients' quality of life was assessed by the Incontinence Impact Questionnaire-7 (IIQ-7; 20). The UDI-6 and IIQ-7 consist of six and seven items, respectively, with a four-point Likert-type scale (i.e., not at all, a little bit, moderately, and greatly) (20). The Turkish versions of the UDI-6 and IIQ-7 were found to be reliable (Cronbach's $\alpha$ 0.74-0.87; Spearman's rho 0.99) (20). Cam et al. (20) have reported that these tools are reliable questionnaires for patients with UI. Higher total scores on the UDI-6 and IIQ-7 indicate greater symptom distress and lower quality of life, respectively (20).

Lastly, a vaginal perineometer with an arbitrary scale of 0 12 was used to determine pelvic floor muscle strength and endurance. Before the evaluation, an experienced physiotherapist provided information on the right pelvic floor muscle contraction using digital palpation. The probe of the perineometer was inserted to the level of the hymenal ring for the purpose of standardization (21). The women were asked to contract their pelvic floor muscles and to maintain this contraction for 10 seconds without the Valsalva maneuver, straining, or the contraction of the abdominal, abductor, or gluteal muscles (22). Three contractions were performed with 30 -second rest intervals. For each contraction, the rest value before the pelvic floor contraction, the maximum value during the contraction, and the values at the end of the 10 -second contractions were recorded (23). The participants' pelvic floor muscle strength 
and endurance were calculated based on the mean values of the three contractions (22-23).

\section{Data Analysis}

Data analysis was conducted using the Statistical Package for the Social Sciences (SPSS) software, version 21 (IBM SPSS Statistics; IBM Corporation, Armonk, NY). The normality distribution of the data was checked using the Kolmogorov-Smirnov test. A one-way analysis of variance test (ANOVA) was used to analyze the differences in the normally distributed continuous data among the study groups. The differences in the non-normally distributed quantitative data were examined using the Kruskal-Wallis test. When an overall significance was observed, pair-wise analysis (i.e., mild UI and moderate UI; mild UI and severe UI; moderate UI and severe UI) was performed by the Mann-Whitney U test with the Bonferroni correction. The corrected $p$-value was accepted as $<0.016$ for the pair-wise comparisons. The differences in categorical variables were compared through the Chisquare test. The associations between the severity of UI and all outcome measures were analyzed using the Spearman correlation analysis. A $p$ value of $<0.05$ was assumed as the level of statistical significance.

\section{Results}

A total of 164 patients with UI were screened for inclusion. Ten patients did not want to participate in the study, and 22 patients were excluded due to $P O P \geq$ Stage $3(n=8)$, a current urinary tract infection $(n=5)$, a diagnosis of neurological disease $(n=4)$, or insufficient literacy for the completion of assessments $(n=5)$. The measurement of pelvic floor function could not be performed in 12 patients. Therefore, 120 patients with a symptomatic diagnosis of UI participated in and completed the study protocol.

Socio-demographic, physical, and clinical characteristics of the participants

In the total population $(\mathrm{n}=120)$, the median age was 49.0 years, and the mean BMI was $28.0 \pm 4.0 \mathrm{~kg} / \mathrm{m}^{2}$. Of the participants, $41 \%$ of the women were in the post-menopausal period. The distribution of UI according to UI severity was 31 participants $(25.8 \%)$ with mild UI, 41 (34.1\%) participants with moderate UI, and 48 (40\%) participants with severe UI. The prevalence rates of SUI and MUI were found to be $54.2 \%$ and $45.8 \%$, respectively. Socio-demographic, physical, and clinical characteristics are presented in table I.

There were no significant differences in terms of age, BMI, marital status, gravidity, parity, or smoking status among the study groups $(p>0.05)$. Based on the results of the overall comparisons, significant differences were found in the education level, employment status, post-menopausal status, and the duration of UI $(p<0.05)$. Post-hoc comparisons revealed that education level was significantly higher in the mild UI group than in the severe UI group ( $p=0.003)$. Additionally, patients with severe UI had significantly longer durations of incontinence than those with mild UI ( $p=0.002)$. Furthermore, based on the pair-wise analyses, the participants with severe UI had a significantly lower rate of employment than those with mild and moderate UI $(p<0.001$ and $p=0.01$, respectively). The prevalence rate of post-menopausal status was lower in the mild UI group compared to the moderate and severe UI groups ( $p=0.003$ and $p<0.001$, respectively). Lastly, there was a significant difference in the type of UI among patients with mild, moderate, and severe UI $(p<0.001$; Table I). Pairwise analyses

Table I: Demographic, physical, and clinic characteristics of the participants

\begin{tabular}{|c|c|c|c|c|c|}
\hline Variables & $\begin{array}{l}\text { Total patients } \\
\quad(n=120)\end{array}$ & $\begin{array}{l}\text { Mild UI } \\
(n=31)\end{array}$ & $\begin{array}{l}\text { Moderate UI } \\
\quad(n=41)\end{array}$ & $\begin{array}{l}\text { Severe UI } \\
\quad(n=48)\end{array}$ & $p$ \\
\hline Age (years) $\dagger$ & $49.0(44.2-55.0)$ & $48.0(42.0-52.0)$ & $50.0(45.0-56.0)$ & $50.0(44.2-55.0)$ & 0.15 \\
\hline BMI $\left(\mathrm{kg} / \mathrm{m}^{2}\right) \ddagger$ & $28.0 \pm 4.0$ & $27.3 \pm 5.1$ & $27.6 \pm 3.7$ & $28.8 \pm 3.4$ & 0.13 \\
\hline Education (years)† & $11.0(11.0-15.0)$ & $15.0(11.0-15.0)$ & $13.0(11.0-15.0)$ & $11.0(8.0-15.0)$ & 0.013 \\
\hline Married (yes)* & $104.0(86.7 \%)$ & $26.0(83.9 \%)$ & $39.0(95.1 \%)$ & $39.0(81.3 \%)$ & 0.13 \\
\hline Employed (yes) ${ }^{*}$ & $58.0(48.3 \%)$ & $21.0(67.7 \%)$ & $23.0(56.1 \%)$ & $14.0(29.2 \%)$ & 0.002 \\
\hline Gravidity $(n) \dagger$ & $3.0(2.0-5.0)$ & $3.0(2.0-5.0)$ & $3.0(2.0-4.0)$ & $3.0(2.0-6.0)$ & 0.22 \\
\hline Parity $(n) \dagger$ & $2.0(2.0-3.0)$ & $2.0(2.0-2.0)$ & $2.0(1.5-2.0)$ & $2.0(2.0-3.0)$ & 0.08 \\
\hline $\begin{array}{l}\text { Post-menopausal } \\
\text { status (yes)* }\end{array}$ & $50.0(41.7)$ & $4.0(12.9)$ & $19.0(46.3)$ & $27.0(56.3)$ & 0.001 \\
\hline Duration of UI (years)† & $4.0(2.0-6.0)$ & $4.0(1.0-5.0)$ & $3.0(2.0-5.5)$ & $5.0(2.2-8.0)$ & 0.012 \\
\hline Type of UI* & & & & & $<0.001$ \\
\hline SUI & $65.0(54.2)$ & $24.0(77.4)$ & $26.0(63.4)$ & $15.0(31.3)$ & \\
\hline MUI & $55.0(45.8)$ & $7.0(22.6)$ & $15.0(36.6)$ & $33.0(68.8)$ & \\
\hline Smoking (yes) ${ }^{*}$ & $17.0(14.2 \%)$ & $4.0(12.9 \%)$ & $9.0(22.0 \%)$ & $4.0(8.3 \%)$ & 0.30 \\
\hline
\end{tabular}

Data are presented as mean \pm standard deviation, median (25\%-75\%), or frequency (\%). BMI: Body mass index, MUI: Mixed urinary incontinence, SUI: Stress urinary incontinence, UI=Urinary incontinence, $t$ : Kruskal-Wallis test for the analysis of non-normally distributed continuous data, $¥:$ Oneway ANOVA for the analysis of normally distributed continuous data, ${ }^{*}$ :Chi-square or Fisher's exact test for the analysis of categorical data. 
revealed that MUI was more prevalent in patients with severe UI than those with mild ( $p<0.001)$ or moderate UI $(p=0.003)$.

Comparing symptom distress, quality of life, and pelvic floor muscle function among the study groups

In the total population, self-reported symptom distress and quality of life were significantly affected based on the severity of UI $(p<0.001)$. The patients with severe UI had higher symptom distress and poorer quality of life than patients with mild or moderate UI $(p<0.001)$. No statistically significant differences in pelvic floor muscle strength and endurance were found among the study groups ( $p>0.05$; Table II).
The subgroup analysis based on the type of UI revealed that patients with severe SUI had a greater decrease in quality of life than those with mild SUI $(p<0.001)$. Additionally, patients with severe MUI reported greater symptom distress and decreased quality of life compared to those with mild ( $p=0.002$ and $p=0.007$, respectively) or moderate MUI $(p<0.001$ and $p<0.001$, respectively; Table III). Similar to the total population analysis, there were no significant differences in pelvic floor muscle strength and endurance among patients with mild, moderate, and severe SUI or MUI $(p>0.05$; Table III).

Table II: Comparisons of symptom distress, quality of life, and pelvic floor muscle function among the study groupst

\begin{tabular}{|c|c|c|c|c|}
\hline Variables & Total $(n=120)$ & Mild UI $(n=31)$ & Moderate UI $(n=41)$ & Severe UI $(n=48)$ \\
\hline UDI-6 score & $25.0(16.6-37.5)$ & $20.8(8.3-33.3)$ & $20.8(12.5-27.0)$ & $37.5(25.0-50.0)$ \\
\hline \multirow{2}{*}{$p$ values } & $p^{\ddagger}$ & $p^{1 \text { (mild-moderate) }}$ & $p^{2 \text { (mild-severe) }}$ & $p^{3 \text { (moderate-severe) }}$ \\
\hline & $<0.001^{*}$ & 0.68 & $<0.001^{* *}$ & $<0.001^{\star *}$ \\
\hline IIQ-7 score & $38.0(23.7-66.6)$ & $23.7(19.0-33.3)$ & $33.3(23.7-59.4)$ & $71.3(39.2-80.8)$ \\
\hline \multirow{2}{*}{$p$ values } & $\mathrm{p}^{\ddagger}$ & $p^{1 \text { (mild-moderate) }}$ & $p^{2 \text { (mild-severe) }}$ & $p^{3 \text { (moderate-severe) }}$ \\
\hline & $<0.001^{*}$ & 0.02 & $<0.001^{* *}$ & $<0.001^{* *}$ \\
\hline PFMS & $5.3(2.6-6.6)$ & $4.9(2.0-5.3)$ & $5.1(2.6-7.0)$ & $5.6(3.3-6.6)$ \\
\hline \multirow{2}{*}{$p$ values } & $p^{\ddagger}$ & $p^{1 \text { (mild-moderate) }}$ & $p^{2 \text { (mild-severe) }}$ & $p^{3 \text { (moderate-severe) }}$ \\
\hline & 0.24 & - & - & - \\
\hline PFME & $66.2(43.1-84.0)$ & $70.6(36.3-85.0)$ & $75.5(53.7-85.2)$ & $61.5(36.6-80.9)$ \\
\hline \multirow{2}{*}{$p$ values } & $p^{\ddagger}$ & $p^{1 \text { (mild-moderate) }}$ & $p^{2 \text { (mild-severe) }}$ & $p^{3 \text { (moderate-severe) }}$ \\
\hline & 0.13 & - & - & - \\
\hline
\end{tabular}

t: Data are presented as Median (25\% - $75 \%$ ), $¥:$ Kruskal-Wallis test for non-normally distributed continuous variables IIQ-7: Incontinence impact questionnaire-7, PFME: Pelvic floor muscle endurance, PFME: Pelvic floor muscle strength, UDI-6: Urinary distress inventory-6, VAS: Visual analog scale, p1: Comparison of differences between mild and moderate group, p2: Comparison of differences between mild and severe group, p3: Comparison of differences between moderate and severe group. Significant differences are in bold. ${ }^{*} p<0.05 .{ }^{* *} p<0.016$.

Table III: Sub-group comparisons of symptom distress, quality of life, and pelvic floor muscle function ${ }^{\dagger}$

\begin{tabular}{|c|c|c|c|c|c|c|}
\hline Variables & $\begin{array}{l}\text { Mild SUI } \\
(n=24)\end{array}$ & $\begin{array}{l}\text { Moderate } \\
\text { SUI }(n=26)\end{array}$ & $\begin{array}{l}\text { Severe SUI } \\
(n=15)\end{array}$ & $\begin{array}{l}\text { Mild MUI } \\
(n=7)\end{array}$ & $\begin{array}{l}\text { Moderate MUI } \\
(n=15)\end{array}$ & $\begin{array}{l}\text { Severe MUI } \\
(n=33)\end{array}$ \\
\hline UDI-6 score & $14.5(8.3-31.2)$ & $18.7(12.5-26.0)$ & $25.0(12.5-50.0)$ & $29.1(20.8-33.3)$ & $25.0(16.6-29.1)$ & $41.6(33.3-50.0)$ \\
\hline \multirow{2}{*}{$p$ values } & $p^{1}$ (mild-moderate) & $p^{2 \text { (mild-severe) }}$ & $p^{3 \text { (moderate-severe) }}$ & $p^{1 \text { (mild-moderate) }}$ & $p^{2 \text { (mild-severe) }}$ & $p^{3 \text { (moderate-severe) }}$ \\
\hline & 0.26 & 0.02 & 0.09 & 0.13 & $0.002^{*}$ & $<0.001^{*}$ \\
\hline IIQ-7 score & $21.4(19.0-32.1)$ & $30.9(19.0-63.0)$ & $47.5(33.3-71.3)$ & $38.0(33.3-47.5)$ & $33.3(23.7-47.5)$ & $71.3(47.5-80.8)$ \\
\hline \multirow{2}{*}{$p$ values } & $p^{1}$ (mild-moderate) & $p^{2 \text { (mild-severe) }}$ & $p^{3 \text { (moderate-severe) }}$ & $p^{1 \text { (mild-moderate) }}$ & $p^{2 \text { (mild-severe) }}$ & $p^{3 \text { (moderate-severe) }}$ \\
\hline & 0.016 & $<0.001^{*}$ & 0.13 & 0.43 & $0.007^{*}$ & $<0.001^{*}$ \\
\hline PFMS & $4.9(2.0-5.3)$ & $5.9(2.7-7.1)$ & $5.3(4.2-6.8)$ & $4.3(3.4-5.3)$ & $3.6(2.3-6.0)$ & $5.7(2.8-6.7)$ \\
\hline \multirow{2}{*}{$p$ values } & $p^{1}$ (mild-moderate) & $p^{2 \text { (mild-severe) }}$ & $p^{3 \text { (moderate-severe) }}$ & $p^{1}$ (mild-moderate) & $p^{2 \text { (mild-severe) }}$ & $p^{3 \text { (moderate-severe) }}$ \\
\hline & 0.11 & 0.19 & 0.96 & 0.99 & 0.58 & 0.43 \\
\hline PFME & $74.2(47.9-85.0)$ & $76.1(48.9-86.2)$ & $61.4(32.0-75.3)$ & $54.7(36.3-85.8)$ & $56.1(52.7-79.9)$ & $62.2(46.0-81.8)$ \\
\hline \multirow{2}{*}{$p$ values } & $p^{1 \text { (mild-moderate) }}$ & $p^{2 \text { (mild-severe) }}$ & $p^{3 \text { (moderate-severe) }}$ & $p^{1 \text { (mild-moderate) }}$ & $p^{2 \text { (mild-severe) }}$ & $p^{3 \text { (moderate-severe) }}$ \\
\hline & 0.67 & 0.02 & 0.05 & 0.83 & 0.98 & 0.83 \\
\hline
\end{tabular}

t: Data are presented as median (25\%-75\%), $¥:$ Kruskal-Wallis test for non-normally distributed continuous variables, IIQ-7: Incontinence impact questionnaire-7, MUI: Mixed urinary incontinence, PFME: Pelvic floor muscle endurance, PFME: Pelvic floor muscle strength, UDI-6: Urinary distress inventory-6, SUI: Stress urinary incontinence, VAS: Visual analog scale, p1: Comparison of differences between mild and moderate group, p2: Comparison of differences between mild and severe group, p3: Comparison of differences between moderate and severe group. Significant differences are in bold. * $p<0.016$. 
Associations between the severity of UI and symptom distress, quality of life, and pelvic floor muscle function

In the total population, it was found that the increased severity of UI was significantly associated with higher levels of symptom distress $(p<0.001)$ and lower quality of life $(p<0.001$; table IV). The subgroup analyses of the patients with SUI and MUI also revealed that there were significant relationships between the severity of UI and symptom distress ( $p=0.007$ and $p<0.001$, respectively) and quality of life $(p<0.001)$. However, the analysis of the total population and the subgroup analyses of the types of UI revealed that no association was found between the severity of UI and pelvic floor muscle strength and endurance ( $p>0.05$; table IV).

\section{Discussion}

In the present study, it was found that patients with severe SUI experienced greater decreased the quality of life than those with mild SUI. Additionally, women with severe MUI reported higher symptom distress and greater decreased quality of life compared to women with mild and moderate MUI. Furthermore, the severity of UI was demonstrated to be associated with symptom distress and quality of life. However, no significant differences in pelvic floor muscle strength and endurance were found among the study groups.

Similar to a previous study conducted by Gasquet et al. (6), we found that women with severe UI had a lower education level than those with moderate UI and that employment rates decreased as the severity of symptoms increased. It has been indicated that the education level of patients can be a factor that may affect the patients' perspectives of UI (24). Compared to women with a higher educational level, women with a lower education level more frequently reported health-related impairments, and they were more likely to indicate UI as a disturbing health condition (25). Furthermore, decreased health literacy due to lower educational status may be associated with inaccurate disease beliefs. Many women may also believe that UI is a natural aspect of aging (15). Additionally, lower socioeconomic status may prevent access to health care facilities in time for treatment (15). For these reasons, the lower educational and economic status may be related to severe UI.

In addition, we found that the clinical severity of UI symptoms was associated with a longer duration of symptoms.
Furthermore, we found that the number of post-menopausal women was higher in the severe UI group. The present results are validated by previous research that investigated the impact of the severity of UI on quality of life (6). In the literature, it was demonstrated that menopausal status due to estrogen loss is related to the presence and the severity of UI (26).

Based on the literature, there is no consensus regarding an assessment method for the severity of UI. Similar to previous studies (9,27-29), we evaluated the severity of UI using the validated ISI. Other studies have used various measurement methods for the evaluation of UI severity, including the 24hour pad test (30), self-perceived incontinence severity (mild, moderate, or severe; 12), and an invalidated questionnaire (6). It was reported that the 24-hour pad test does not have a standardized protocol and that urine leakage can differ based on the patient's physical activity level (30). In clinical settings, subjective measurements for the determination of the severity of UI are preferred due to their cost-effectiveness, time-efficacy, and good correlation with objective measurements. In women with UI, the ISI was found to have a good correlation with urinary leakage based on the 48-hour pad test (19). Additionally, Melville et al. (31) found that there was a high correlation between physician and patient assessments of incontinence severity.

Previous studies have investigated the effect of UI severity on quality of life in different patient populations, including European (6,9,29,30), American (27-28), and Asian (12) populations. Monz et al. (29) reported that the severity of UI was the single most important predictor, regardless the type of UI, in European women. Similar to the findings of the present study, another study found that the severity of UI symptoms was associated with the perception of quality of life (6). A recent study indicated that there was no linear correlation between incontinence severity, assessed by the 24-hour pad test, and quality of life, measured by the King's Health Questionnaire (30). In addition, researchers have reported that patients with any amount of urine leakage should be paid attention to, as the influence of UI on quality of life is more qualitative than quantitative (30).

To maintain bladder continence, the function of the pelvic floor muscles has been considered as an important factor (14). In the literature, it has been reported that women with UI

Table IV: Correlations among UI severity and symptom distress, quality of life, and pelvic floor muscle function

\begin{tabular}{llll}
\hline & $\begin{array}{l}\text { ISI score (total) } \\
\text { r } ; p\end{array}$ & $\begin{array}{l}\text { ISI score (SUI) } \\
\mathrm{r}^{\dagger} ; p\end{array}$ & $\begin{array}{l}\text { ISI score (MUI) } \\
\mathrm{r}^{\dagger} ; p\end{array}$ \\
\hline UDI-6 & $0.53 ;<0.001$ & $0.33 ; 0.007$ & $0.67 ;<0.001$ \\
IIQ-7 & $0.69 ;<0.001$ & $0.51 ;<0.001$ & $0.63 ; 0.001$ \\
Pelvic floor muscle strength & $0.09 ; 0.33$ & $0.20 ; 0.13$ & $-0.07 ; 0.62$ \\
Pelvic floor muscle endurance & $-0.12 ; 0.23$ & $-0.14 ; 0.29$ & $0.07 ; 0.62$ \\
\hline
\end{tabular}

t: Correlations were analyzed using the Spearmen's correlation analysis, IIQ-7: Incontinence Impact Questionnaire-7, ISI: Incontinence severity index, MUI: Mixed urinary incontinence, SUI: Stress urinary incontinence, UDI-6: Urinary distress inventory-6, UI: Urinary incontinence 
have greater decreased muscle strength than those without UI (32-33). In the present study, we could not find an inverse relationship between the severity of UI and pelvic floor muscle strength and endurance, as expected. This finding was also supported by a previous study that investigated the association between pelvic floor muscle strength, measured by the Brink score, and the severity of UI, evaluated by the pad test (14). FitzGerald et al. (14) reported that the relative homogeneity, due to a relatively small range of Brink scores, and the lack of inclusion of a continent control group may fail to reflect a possible association between the severity of UI and pelvic floor muscle strength. In the present study, we believe that these results may be related to the lack of a control group that included women without UI and related to the assessment of the pelvic floor function using only a perineometer. Further studies may include the assessment of pelvic floor muscle activity using electromyography in order to investigate the relationship between pelvic floor muscle function and the severity of UI.

\section{Study limitations}

The findings of the present study should be interpreted in light of the study's limitations. First, the design of the present study was cross-sectional, and the evaluations were performed at only one point in time. Therefore, further longitudinal studies should be planned in order to obtain more accurate results concerning the differences in symptom distress, quality of life, and pelvic floor muscle function in patients with UI at different levels of disease severity. A second limitation was that the generalizability of the findings might be affected due to the recruitment of the patients from only one center. To increase the generalizability, further populationbased studies involving patients from general and different samples can be planned.

\section{Conclusion}

This study concluded that patients with severe SUI had greater decreased quality of life than those with mild SUI. Additionally, severe MUI had more impact on symptom distress and quality of life than mild or moderate MUI. In addition, the severity of SUI or MUI was associated with symptom distress and quality of life in Turkish women. To prevent a greater impact of incontinence on the quality of life of women with UI, early detection of UI and early management based on the severity of incontinence are important strategies. For this reason, the relationship between the severity of UI and quality of life should be evaluated in clinical settings. Further longitudinal studies with larger sample sizes are needed to demonstrate clearer findings regarding the effects of incontinence severity on symptom distress and quality of life in Turkish women with UI.

Acknowledgements: None.

Funding and Conflict of Interest: The authors have no funding or conflict of interest to disclose.
Authors Contributions: CO: Project development, design, data collection, analysis/interpretation, literature search, writing, and critical review. SO: Project development, design, data collection, literature search, critical review, and supervision. EB: Project development, design, and data collection. EU: Project development, design, and data collection. GN: Project development, design, data collection. GNC: Project development and data collection. MSB: Project development, design, critical review, and supervision. TA: Project development, design, writing, critical review, and supervision.

\section{References}

1. Haylen BT, de Ridder D, Freeman RM, Swift SE, Berghmans $\mathrm{B}$, Lee $\mathrm{J}$, et al. An International Urogynecological Association (IUGA)/International Continence Society (ICS) joint report on the terminology for female pelvic floor dysfunction. Int Urogynecol J. 2010;21(1):5-26.

2. Ekin M, Karayalçın M, Ozcan U, Erdemlioglu E. The prevalence of urinary incontinence and its influence on the quality of life in women of reproductive and postmenopausal age groups. J Ank Med Sch. 2004;26(1):21-5.

3. Filiz TM, Uludag C, Cinar N, Gorpelioglu S, Topsever P. Risk factors for urinary incontinence in Turkish women. A cross-sectional study. Saudi Med J. 2006;27(11):1688-92.

4. Ozerdogan N, Beji NK, Yalcin O. Urinary incontinence: its prevalence, risk factors and effects on the quality of life of women living in a region of Turkey. Gynecol Obstet Invest. 2004;58(3):145-50.

5. Demir O, Sen V, Irer B, Bozkurt O, Esen A. Prevalence and possible risk factors for urinary incontinence: A cohort study in the city of Izmir. Urol Int. 2017;99(1):84-90.

6. Gasquet I, Tcherny-Lessenot S, Gaudebout P, Bosio Le Goux B, Klein P, Haab F. Influence of the severity of stress urinary incontinence on quality of life, health care seeking, and treatment: A national cross-sectional survey. Eur Urol. 2006;50(4):818-25.

7. Xu D, Liu N, Qu H, Chen L, Wang K. Relationships among symptom severity, coping styles, and quality of life in community-dwelling women with urinary incontinence: a multiple mediator model. Qual Life Res. 2016; 25(1):223-32.

8. Nystrom E, Sjostrom M, Stenlund H, Samuelsson E. ICIQ symptom and quality of life instruments measure clinically relevant improvements in women with stress urinary incontinence. Neurourol Urodyn. 2015;34(8):747-51.

9. Barentsen JA, Visser E, Hofstetter H, Maris AM, Dekker $\mathrm{JH}$, de Bock GH. Severity, not type, is the main predictor of decreased quality of life in elderly women with urinary incontinence: a population-based study as part of a randomized controlled trial in primary care. Health Qual Life Outcomes. 2012;10:153.

10. Coyne KS, Zhou Z, Thompson C, Versi E. The impact on 
health-related quality of life of stress, urge and mixed urinary incontinence. BJU Int. 2003;92(7):731-5.

11. Lagro-Janssen TL, Smits AJ, Van Weel C. Women with urinary incontinence: self-perceived worries and general practitioners' knowledge of problem. Br J Gen Pract. 1990;40(337):331-4.

12. Oh SJ, Ku JH, Hong SK, Kim SW, Paick JS, Son H. Factors influencing self-perceived disease severity in women with stress urinary incontinence combined with or without urge incontinence. Neurourol Urodyn. 2005;24 (4):341-7.

13. Obloza A, Teo R, Marriott E, Parker G, Tincello D. Association of baseline severity of lower urinary tract symptoms with the success conservative therapy for urinary incontinence in women. Int Urogynecol $\mathrm{J}$. 2019;30(5):705-10.

14. FitzGerald MP, Burgio KL, Borello-France DF, Menefee SA, Schaffer J, Kraus S, et al. Pelvic-floor strength in women with incontinence as assessed by the brink scale. Phys Ther. 2007;87(10):1316-24.

15. Akkus Y, Pinar G. Evaluation of the prevalence, type, severity, and risk factors of urinary incontinence and its impact on quality of life among women in Turkey. Int Urogynecol J. 2016;27(6):887-93.

16. Brubaker L, Lukacz ES, Burgio K, Zimmern P, Norton P, Leng W, et al. Mixed incontinence: comparing definitions in non-surgical patients. Neurourol Urodyn. 2011;30(1): 47-51.

17. Herzog AR, Diokno AC, Brown MB, Normolle DP, Brock BM. Two-year incidence, remission, and change patterns of urinary incontinence in noninstitutionalized older adults. J Gerontol. 1990;45(2):M67-74.

18. Sandvik H, Hunskaar S, Seim A, Hermstad R, Vanvik A, Bratt $\mathrm{H}$. Validation of a severity index in female urinary incontinence and its implementation in an epidemiological survey. J Epidemiol Community Health. 1993;47(6):497-9.

19. Sandvik H, Seim A, Vanvik A, Hunskaar S. A severity index for epidemiological surveys of female urinary incontinence: comparison with 48-hour pad-weighing tests. Neurourol Urodyn. 2000;19(2):137-45.

20. Cam C, Sakalli M, Ay P, Cam M, Karateke A. Validation of the short forms of the incontinence impact questionnaire (IIQ-7) and the urogenital distress inventory (UDI6) in a Turkish population. Neurourol Urodyn. 2007;26 (1):129-33.

21. Isherwood PJ, Rane A. Comparative assessment of pelvic floor strength using a perineometer and digital examination. BJOG. 2000;107(8):1007-11.

22. Orhan C, Akbayrak T, Ozgul S, Baran E, Uzelpasaci E,
Nakip G, et al. Effects of vaginal tampon training added to pelvic floor muscle training in women with stress urinary incontinence: randomized controlled trial. Int Urogynecol J. 2019;30(2):219-29.

23. Kaya S, Akbayrak T, Gursen C, Beksac S. Short-term effect of adding pelvic floor muscle training to bladder training for female urinary incontinence: a randomized controlled trial. Int Urogynecol J. 2015;26(2):285-93.

24. Kaya S, Akbayrak T, Orhan C, Beksac S. Kadınlarda farklı üriner inkontinans tiplerinde hasta özelliklerinin ve üriner parametrelerin karşılaştırılması: retrospektif bir çalışma. J Exerc Ther Rehabil. 2015;2(3):93-101.

25. van der Vaart $\mathrm{CH}$, van der Bom JG, de Leeuw JR, Roovers JP, Heintz AP. The contribution of hysterectomy to the occurrence of urge and stress urinary incontinence symptoms. BJOG. 2002;109(2):149-54.

26. Milsom I, Ekelund P, Molander U, Arvidsson L, Areskoug B. The influence of age, parity, oral contraception, hysterectomy and menopause on the prevalence of urinary incontinence in women. J Urol. 1993;149(6):1459-62.

27. Aguilar-Navarro S, Navarrete-Reyes AP, GradosChavarria BH, Garcia-Lara JM, Amieva H, Avila-Funes JA. The severity of urinary incontinence decreases healthrelated quality of life among community-dwelling elderly. J Gerontol A Biol Sci Med Sci. 2012;67(11):1266-71.

28. Minassian VA, Devore E, Hagan K, Grodstein F. Severity of urinary incontinence and effect on quality of life in women by incontinence type. Obstet Gynecol. 2013;121 (5):1083-90.

29. Monz B, Chartier-Kastler E, Hampel C, Samsioe G, Hunskaar S, Espuna-Pons M, et al. Patient characteristics associated with quality of life in European women seeking treatment for urinary incontinence: results from PURE. Eur Urol. 2007;51(4):1073-81; discussion 1081-2.

30. Krhut J, Gartner M, Mokris J, Horcicka L, Svabik K, Zachoval R, et al. Effect of severity of urinary incontinence on quality of life in women. Neurourol Urodyn. 2018:37(6):1925-30.

31. Melville JL, Miller EA, Fialkow MF, Lentz GM, Miller JL, Fenner DE. Relationship between patient report and physician assessment of urinary incontinence severity. Am J Obstet Gynecol. 2003;189(1):76-80.

32. Morin M, Bourbonnais D, Gravel D, Dumoulin C, Lemieux MC. Pelvic floor muscle function in continent and stress urinary incontinent women using dynamometric measurements. Neurourol Urodyn. 2004;23(7):668-74.

33. Mørkved S, Bø K, Schei B, Salvesen KA. Pelvic floor muscle training during pregnancy to prevent urinary incontinence: a single-blind randomized controlled trial. Obstet Gynecol. 2003;101(2):313-9. 